\title{
Lessons from EEO: Toward a Universal Evolutionary Curriculum
}

\author{
Niles Eldredge • Gregory Eldredge
}

Published online: 21 November 2009

(C) Springer Science + Business Media, LLC 2009

\begin{abstract}
We propose a human-centered evolutionary curriculum based around the three questions: Who am I? Where do I come from? How do I fit in? We base our curriculum on our experiences as an evolutionary biologist/ paleontologist (NE) and as a secondary level special education science teacher (GE) - and not least from our joint experience as co-editors-in-chief of this journal. Our proposed curriculum starts and ends with human biology and evolution, linking these themes with topics as diverse as the "tree of life" (systematics), anthropology, Charles Darwin, cultural evolution, ecology, developmental biology, molecular evolution/genetics, paleontology, and plate tectonics. The curriculum is "universal" as it is designed to be taught at all levels, $\mathrm{K}-16$. The curriculum is flexible: "modules" may be expanded and contracted, reordered, or modified to fit specific grade level needs - and the requirements and interests of local curricula and teachers. We further propose that students utilize workbooks from online or printed sources to investigate the local answers to the general questions (e.g., "Who am I?"), while classroom instruction is focused on the larger scale issues outlined in the modules of our curriculum.
\end{abstract}

Keywords Evolution curriculum · Anthropology · Cultural evolution - Systematics · Tree of life - Ecology · Paleontology · Molecular evolution · Genetics .

Plate tectonics - Developmental biology · Charles Darwin . $\mathrm{K}-16$ evolutionary education

\footnotetext{
N. Eldredge $(\bowtie)$

Division of Paleontology, American Museum of Natural History, New York, NY, USA

e-mail: epunkeek@amnh.org

G. Eldredge

Port Jervis Middle School,

Port Jervis, NY, USA
}

Change is in the air. With President Obama signaling a renewed commitment to quality public education in the United States and, in particular, in light of his recognition of the critical need to improve science education, now is the time for all of us, whether in science or education, to redouble our efforts to improve the science curriculum in general - and, from the perspective of those of us here at Evolution: Education and Outreach (hereafter EEO), especially in the general arena of evolutionary science.

As founding co-editors-in-chief of this journal-one of us a special education science teacher, the other an evolutionary-minded paleobiologist — we have had the privilege of seeing and hearing - and learning - a lot as we have organized both scientific and educational special issues. All the while, we have been fortunate to receive a (steadily increasing) flow of quality submissions ranging from grammar and junior high school evolutionary teaching (e.g., Fail (2008) in our inaugural issue, focusing especially on natural selection in the curriculum but also making the point that teachers should not shy away from teaching human evolution; see also the special issue devoted to curriculum and teaching subjects-Jenkins (2009)) to the emergence of human consciousness (Tattersall 2009b, this issue). Now, more than ever, we are convinced that the concept of evolution, vital in its own right as one of the great ideas, not only in the history of science but in the entire history of Western world culture, needs to find an ever stronger, more central curricular presence as we seek better, more effective ways to educate our kids.

The reason is simple: evolution is, in its extended thematic content, manifestly more about the kids themselves than the subject matter of any other scientific discipline. We are convinced that the emerging emphasis on making curricula content meaningful on a personal level to students - including the use of story lines $(\mathrm{N}$. Eldredge 2009a) - has the very real potential to defuse the 
entrenched fear of science as either too boring, completely irrelevant or too "hard." Viewed this way, evolution broadly construed can be one of the most effective ways to teach science in general. Indeed, as developed in another essay in this issue (D. Eldredge 2009), evolution has the very real promise of linking up the subject matters of disciplines usually considered to be far outside the conventional boundaries of science.

Thus our experiences here at the journal over the past two years-including the fact that, though we are father and son, we now speak more directly to each other in professional terms than ever we have in the past-have led us to search for an approach to teaching evolution in all its diverse array of subject matter-which include the basics of evolutionary biology, diverse as they in themselves are; but also how the biological world and its evolution are linked to the physical environment; how we as humans have unique insights on what it is to be alive; and how our cultures have evolved as well as our physical beings - among many other topics.

We seek as well an approach that allows the basic organization of the subject matter to be adaptable to a diverse array of classroom and individualized instructional circumstances - from grammar school right on up through college ("K-16"), from special educational programs through advanced placement and from the standpoint of integration of science with other vital nonscience elements of the general curriculum. Hence, we seek a "universal" comprehensible and flexible evolutionary curriculum: easily adapted to diverse grade levels, rich in the subject areas of greatest interest and importance to teachers, workable within the demands of state testing standards and other existing structures.

In order to maximize the personal interest awakened in a given student, we also envisage teaching evolutionary science from a local perspective - an experience-based, interactive a approach where students investigate the basic questions at their local level as they simultaneously learn the generalities of the concepts, buttressed by examples drawn from all over the world, in a more conventional classroom setting. Our student-oriented approach to learning has a long history, reaching back through Dewey to Socrates and employing modern concepts such as discovery-based learning, metacognition and problem-based learning. Whatever the terminology, we believe both the technology and skill of teachers are already at hand for this ambitious dual, interactive approach. For the students, the problem is not where they live but how they live. Mostly divorced from a life of outdoor activity and exploration, our children, as they become progressively more obese, have been diagnosed with a national case of "nature deficit disorder." In spite of this, nature remains. All that is needed is a teacher who will take students outside. Or provide them with workbook projects designed for independent exploration of the surrounding world, whatever the environment. After all, students are matter/energy transfer packets themselves. The connection between self and the starlight of astronomy is bound up in every bite of food they take. And their inner workings reflect the chemistry and physics of their surroundings, connecting them on an elemental level with the Earth itself.

There is always an "outdoors"- from the pristine rivulets and woodlands that have managed to hang on so far; to the less primordially pure farmlands, nonetheless rife with wildlife; to the fragmented woodlots and fields of suburbia - with the ever-encroaching bears, wild turkeys, and (of course) deer that are re-invading ancestral space (if not habitat); to the broken glass-studded empty lots and deeply polluted streams in and around inner citiesthemselves host to a riot of native and invasive species; and to the city buildings themselves, built of granites and gabbros from around the world, and of limestones and marbles studded with fossils of ages past. Cities offer something special as well-museums and other cultural institutions that bring nature directly to the city. And, used judiciously, there are films, TV - and the Internet-hardly "outdoors" in the classic sense, but nonetheless a window affording access to the natural world. The Hall of Biodiversity at the American Museum of Natural History in New York features a "wall of life" that shows, in evolutionary, tree-of-life phylogenetic fashion, a pot pourri of species from each of the major subdivisions of the fungal, plant and animal kingdoms (along with a healthy subset of microbial life) - using preserved specimens and models. But that wall literally comes to life through the strategic sprinkling of color films showing the animals (and plants-dripping with water and bending to the wind) actually engaged in the process of living.

\section{Toward a Universal Evolutionary Curriculum}

Our universal evolutionary curriculum calls for an interactive text (i.e., with online and supplemental printed materials). It firmly roots biological science at the heart of modern culture; recognizes the two essential twin themes of biology: matter/energy transfer (from cellular processes through ecosystems) and genetic information (from molecular biology, reproduction, evolution); and connects biological subject matter with other scientific disciplines (environmental sciences, including astronomy, climatology, geology, and beyond: to physics and chemistry). We include human cultural diversity in addition to human biological diversity, and we shall also call for inclusion of ancillary applied fields such as medicine and agriculture. 
Three questions lie at the very heart of our approach to teaching evolution to everybody-both locally and in general: Who am I? Where did I come from? How do I fit in? These three key questions in effect use the student's own personal existence to establish a narrative of the living world: stories of what life in effect is, how life arose and evolved through time, how the Earth and its climate have changed, how people have evolved and spread around the globe, and how culture itself has developed and spread over the Earth. The stories include episodes in the history of scientific discovery, as well as stories of how ordinary people - including students - have contributed to the construction of the great story of life on Earth.

The three core questions also raise the issue of how kids view themselves, and by simple extension, their families, friends, neighbors - and neighborhoods. Most children feel that their neighborhoods - and by extension, they themselves - are "nothing special." They do not realize that they and their hometowns are all a part of the puzzle - the larger picture of life on Earth. All places have unique stories - how the landscape formed, how the plants, animals and microbes living there come in unique combinations peculiar to local environments; and how the particular combination of people living there came to be there in the first place. In short, how where they live is a vital and unique part of the story of life on Earth.

We envision developing the themes of "Who am I?" "Where did I come from?" How do I fit in?" with online workbooks that are interactive with print textbooks. The printed text tells the biological story of life on Earth in general terms - albeit charged with many vivid examples drawn from all over the world. The workbooks, in contrast, anchor the storyline in the here and now of the local community where the student lives. In this local, issuesbased learning approach, students will explore the biological and physical world around them by utilizing Internet and conventional resources to answer questions specifically linked to the ecological, evolutionary, and environmental themes encountered in the central text.

Ours is a modular approach: The essential component modules are summarized in concise outlines of the basic themes briefly set forth below. The teacher(s) utilizing our curriculum (with its main book and supplemental materials) will have the flexibility of choosing an expanded content for each of the main subject areas-achieved either with online, downloadable resources, or if the option of ondemand printing is available, through texts tailored specifically for particular school(s)/districts.

For our approach to work, preparation of flexible printed materials (including - but by no means using solelyInternet resources) is essential. Organizing a good text, aimed at a target audience (upper grades in high school, say, or non-majors college biology—or the emerging market of community colleges), while no easy matter in and of itself, at least leads to the familiar textbook formatenhanced as it is these days by separate texts for teachers, on-line chat rooms, blogs - and of course straight-ahead Internet resources, whether prepared to enhance the text or chosen separately by the teacher.

How then to achieve the "accordion"-like flexibility of intensifying some of the core modules outlined below-and perhaps reducing others that seem less relevant to the specific teaching needs of a teacher, a district, or even a region? And what about the materials used by students to bring out their own local experiences in a problem-based learning context? The revolution in personal publishingwhere books are printed "on demand"-is an exciting new development. It is now possible to write and design a book and "publish" as a stand-alone single volume through any of a number of online on demand publishing outlets. The beauty of this approach is that the warehousing of extended print runs is eliminated. A second major advantage is that changes can quickly be made to a text-each time more copies are ordered. The implication of this latter point is simply that books can be targeted for specific educational needs in consultation with teachers and local school boards. The only drawback in this publishing model is, of course, distribution-but if the materials (books and localized workbooks) are produced through a recognized textbook publisher, the problem of distribution is eliminated.

Thus the economics of publishing texts tailored for precise school districts, even single schools, is increasingly coming into the realm of possibility. The core modules we have called for in our curriculum above can be expanded or compressed by prior arrangement - with the precise number of copies specified, printed, and shipped. What follows is a preliminary attempt to outline to an irreducible minimum the core modules, accompanied with a suggestion, at least, of their content. Modules can in some cases be taken up in different orders - and, as above, be expanded/contracted virtually ad infinitum. Though our aim is indeed to develop a curriculum applicable to all grade levels, it is helpful, in reading the following outline, to imagine the course being taught to high school students - say, an average class of tenth graders.

\section{Who Am I? Where Do I Come From, and How Do I Fit In?: Outline of Main Text and Parallel Workbook Modules}

Module 1. Who Am I? Where Do I Come From? How Do I Fit In?

- For starters, we are all animals: you (the student), your teacher, and we who are writing this book. One of us 
authors, long ago, in a college zoology course where they passed out dead pickled lizards for dissection in our first lab, heard a kid shout out "But where is the meat?" All he saw was guts - and the muscles on the body — which, of course, was the meat. Hmm...he thought, "We have muscles too." Years later, one of his kids got mad at the dinner table when his parents pointed out the similarity of the bones in a chicken wing to the bones of a human arm. "People are not animals!" he insisted. The other one of us (see G. Eldredge (2009)), taking his class to the Darwin Exhibition at the American Museum of Natural History in New York only a few years back, showed his students the cabinet of skeletons at the entrance to the exhibition. One of the kids-who came from a family that doubted evolution, especially the idea that humans have evolved from other forms of life-asked his teacher if that was the skeleton of a baby chimp he was looking at. When told that it was, the kid said something to the effect of, "say no more-I get it!" He saw how similar we are to chimps - and by simple extension - to other vertebrates, and eventually to all forms of life.

- So we are a part of the living world, but a special partbecause we can look around us (and those of us who cannot see with their eyes have many other ways of "seeing"); we can think about what we see; we can talk with one another about what we see; and we can learn from the accumulated knowledge and wisdom of all those who came before us who also asked the questions: Who am I? Where did I come from? How do I fit in? from time immemorial. We are special because we know we are alive! Some other species-like your pet dog or maybe the porpoises in the ocean-seem to have some form of awareness, but nothing like what we people have.

- This knowledge - and our ability to think and especially to speak about it - is what makes us not only unique and special - but also the most powerful species of any on Earth. We have no sharp teeth like a tiger or special protection like a thick-skinned rhino, but our knowledge, awareness, and communication skills - our culture - has given us a special place in the living world. Indeed, now that there are almost seven billion people living on planet Earth right now, our abilities to hunt and otherwise transform the environment have begun to cause other species to become extinct. The future of life now seems to be largely in our own hands. How did this happen? What shall we do?

- Most biology texts start out, logically enough, with the simplest forms of life - and humans appear only at the end of the book-which also makes sense, as human evolved only comparatively recently: life began 3.5 billion years ago (as simple bacteria), and we modern humans did not appear until about 200,000 years ago (though we can see a long line of increasingly humanlike species covering about the last seven million years in the fossil record).

- Humans are central to the story of life on Earth right now-and so we start our exploration of the story of life on Earth with the human story - as the old wise saying "know thyself" is probably our very best way of finding out about the entire story of life on Earth.

Module 2. Humans as Part of Life: Who Am I? Writ Large

- What is Life? Here we explore the sometimes conflicting definitions of life itself - establishing that there are two great categories of physicochemical processes that characterize living systems: (1) matter-energy transfer (all organisms require energy and nutrients to develop, grow, and maintain the soma); and (2) the genetic processes underlying reproduction. Humans share with all other organisms both the processing of energy and nutrient resources (the business of living - and staying alive) and reproduction - without which all life (given the impossibility of any one organism to exist ad infinitum-reasons for which can be explored) would eventually cease. Descriptions of systems - reproductive and physiological - as they currently exist on Earth, will constitute a major portion of the evidence that all life is, in fact, interrelated.

- RNA and DNA are the underpinnings of both somatic physiological processes and of reproduction - and are the twin universal features of life on Earth.

- Beginning with the human body, we envision an expandable survey of the basics of human physiology and cellular metabolism, establishing the perspective that humans share these basic vital functions with all other forms of life.

- Likewise, we call for an elastic survey of basic genetic processes of reproduction - again stressing that fundamental aspects of genetic/reproductive processes are common to all forms of life on Earth.

- We then (however briefly) continue the exploration of who we humans are by looking at higher primates, primates in general; seeing what a mammal is and thus, what features are common to all animals; the links extend then to all multicellular forms of life-adding plants, fungi, and some single-celled organisms to the metazoans (all sharing a complex "eukaryotic" cellwhere the main DNA is located on chromosomes inside a double-walled cell nucleus); folding in "bacteria" (the Archaea/Eubacteria issue-see G. Eldredge (2008)), we converge back onto a least common denominator 
sense of what life in general is - which leads, finally, to a consideration of:

- The chicken/egg dilemma - the origin of life on Earth: beginnings of self-replication and the association of proteins with the macromolecules of heredity.

- By now it is clear that all life on Earth is intimately connected - thus, we turn to "evolution."

\section{Module 3. What Is Evolution? How Do Humans Fit} into the History of Life?

- If we are connected to all other forms of life on Earth, and we want to know where we came from-we need to know more about how all forms of life have come into being - and how they are interconnected

- What is "evolution?" Evolution is the testable, scientific idea that all species of life on Earth are descended from a common ancestor living billions of years ago since life first began on Earth. You can think of evolution as the history of life on Earth - or even as the fate of genetic information through time.

-What is a testable scientific idea (hypothesis)? Scientists seek natural, causal explanations to explain natural phenomena; they make predictions about what they would expect to observe if a certain idea is true.

-What would we expect to see if the idea that all organisms are descended from a single ancestor is in fact true?

-We would expect to see:

- A network of similarities linking up all forms of life (see Gregory (2008a)). We have already (Module 2) seen that this is true. The science of mapping out networks of similarities among all organisms is called sytematics. Our species, Homo sapiens, is networked with other species in the Order Primates, Class Mammalia, Phylum Chordata. The "tree of life" is the grand network that links all of life-as predicted by the general notion of evolution.

- A general progression from simpler forms of life ("bacteria") up through the more complex forms of life (see Gregory (2008b) for an entire issue of $E E O$ devoted to complexity). This in fact is what we see in the fossil record of the past 3.5 billion years of life on earth (see below-Module 5-for more detailed treatment on the fossil record of the history of life).

- There are other, more specific, expectations - such as (1) we would expect to see specific overall similarities in structures of species suspected to be related-structures that have been modified in various ways to form particular functions; the forearm of mammals, for example, has an upper single bone (humerus), with the radius and ulna bones below-followed by the "wrist" and then the bones of the "hand": compare the internal structure of wings of bats, the flippers of whales, and the arms of people. (2) We would expect similarities in the developing embryos to increase the earlier in development we look - as we see in the earliest developmental stages of, for example, chickens, mice, and humans. That's what we do see; and (3) modern biology allows us now to compare the details of DNA sequences directly - and we would predict that we would find more genetic similarity between species that we already suspect on other anatomical grounds to be closely related - than between two species thought to be distantly related. For example, we humans share over $98 \%$ of our DNA with chimps - far more than we share with fruit flies; and our genetic resemblance with bananas is (predictably enough) even less.

- The way the logic of testing hypotheses works: you can firmly reject an idea (even one like evolution) if you fail to observe the orderly patterns of similarity predicted to link up all living forms of life; or if the fossil record of the history of life is grossly discordant-for example, if you find elephants in the Precambrian or elephants appearing hundreds of millions of years before dinosaurs.

- This, then, is the evidence for evolution - the patterns of similarity and sequence through time that conforms very closely to the predicted patterns - time after time after time.

- This does not, in the end, absolutely "prove" evolution-but it does make evolution the only scientific notion that explains the structure and history of the diversity of life on Earth.

- Charles Darwin and the founding of the modern theory of evolution: evolution became a credible scientific notion, taken seriously by all scientists directly involved with the study of life on Earth, when Darwin published his book On the Origin of Species by Means of Natural Selection in 1859. Darwin's story is a microcosm of what science is all about: how a young person imbued with the current beliefs of his daywhich were in agreement with religious beliefs on the "fixity of species" (in other words, evolution does not occur), eventually convinced himself that there must be an explanation of the origin of species in natural, scientific terms. Darwin's life as a medical student and later, as a student at Cambridge learning botany and geology; his five years of intense work while on the famous Beagle voyage (see N. Eldredge (2009b)); and his experimental and theoretical work after he returned home to England - is a model of how human beings 
can grapple with the very questions: Who am I? Where did I come from? How do I fit in? Darwin, for one thing, never doubted for a moment, once he had concluded that life in general had evolved, that human beings must also have evolved - and fit into the evolutionary scheme of things along with every other species on Earth.

- Adaptation and natural selection. When Darwin arrived home in England (in 1836) from the Beagle voyage, he soon realized he needed an explanation for why closely related species nonetheless have slight differences between them - how it came to be, for example, that some of the beaks of the various finches on the Galapagos Islands are thick and stubby and others long and more needle-like. He knew in general that such differences reflected a different mode of lifeshort fat beaks for crushing large hard seeds, needlelike beaks for snatching insects from plants.

- Species have behavioral and anatomical specializations that enable them to fit into their environments - to obtain the kinds of food, for example, that they have become accustomed (adapted) to digesting.

- Darwin knew that organisms resemble their parentsand that minor variations could be inherited. He had no idea why (we now know the reasons why - and this module can be expanded here to include, or refresh, the principles of heredity as understood today).

- Darwin then read an essay by Thomas Malthuswho showed that human populations - the numbers of people able to survive - closely follows the food supply. Famine leads to starvation and death; in times of plenty, more babies are born-and, crucially, more babies are able to survive - and the population expands.

- Thus the linchpin of the very concept of natural selection - one of the most important scientific ideas ever discovered-comes directly from someone (Malthus) who was writing about the human condition! Indeed, Karl Marx, whose Das Kapital is the founding document of Communism, criticized Darwin for taking Malthus's ideas - intended for humans - and applying it to all other species on Earth! Yet all Darwin was doing was seeing that what was true for the human condition must be true for all other species!

- Natural selection - the process whereby some genetic variants in a resource-limited population will do better than others in terms of simple survival or flourishing, and thus will tend to leave more offspring (and their genes) to the next generation, remains at the very heart of our understanding of the evolutionary process. Natural selection has been seen operating in the wild; in laboratory populations; and mathematically, in computer simulations as well as in theoretical population genetics.

- Yet adaptation through natural selection-as important as it is-is not the only evolutionary process that has shaped the history of life.

- A species is a group of plants or animals capable of reproducing with one another-in the case of humans and nearly all other animals, where the sexes are separate, mating between a male and a female who recognize one another as potential mates. Thus species are genetic, reproductive entities. Speciation - the origin of new species from ancestral species (and thus a key element to the "Where do I come From?" question)—requires some means of isolating populations within the ancestral species - so that a separate species might eventually emerge. Geographic isolation - where a population of an ancestral species becomes detached from the parental species - is generally thought to be the simplest, most direct way of initiating this isolation. Though Darwin, especially in his earlier notes, saw the importance of geographic isolation in the emergence of new species, this idea was almost lost until resurrected by the geneticist Theodosius Dobzhansky and the ornithologist Ernst Mayr in the 1930s-1940s.

- The idea of "punctuated equilibria" came later in the early 1970 s, in work done by paleontologists Niles Eldredge and Stephen Jay Gould-building on the idea of geographic speciation developed by Dobzhansky and Mayr - and adding in the observation (based on fossils) that species (contrary to the common assumption) do not just keep changingevolving - through time. Most species, in fact, once they evolve, remain relatively unchanged —often for millions of years. Species appear to have births, stable histories, and deaths - much like individual humans do- once again an idea attracting the young Charles Darwin, but largely forgotten by him in his later years-when he wrote the Origin of Species (see Thanukos (2008)).

- And, most recently, paleontologists and evolutionary biologists have rediscovered the reality of mass extinctions - events that five or six times in the past half billion years in the history of life have driven over half the species on Earth extinct. Each time, life has rebounded, as new forms of life have evolved, taking the place of those driven to extinction. These massive extinction events - and the thousands of lesser pulses of extinction that have claimed hundreds of thousands of species 
through geological time - seem essential to further episodes of evolution: without extinction, the evolutionary history of life most likely would have been very different - and some have suggested that we humans would not have evolved at all! (See N. Eldredge (2008), Venditti and Pagel (2008)).

\section{Module 4. Making a Living. How Do Species Fit} into the Natural World?

- Species "fit in" on the tree of life-we have very close extinct relatives; some fairly close modern relatives, and so on: we are part of the spectrum of the living world.

- Organisms "fit into the world" in another, very different way-springing not from reproduction (as in the definition of species and their evolution from one to another) but rather from the other great category of biological process: matter/energy transfer-or, in short, how organisms survive and "make a living" in the world.

- Ecosystems consist of many different kinds of organisms - populations of different species - many of which interacting in a dynamic way-as when birds eat worms, worms churn and aerate the soil, recycling nutrients and making it easier for plants to grow. Matter and energy flow through this dynamic system on a moment-by-moment system. Ecosystems are where most adaptations of organisms are put to use; ecosystems are where the "game of life" is played.

- Ecosystems interconnect over the Earth's surface-as when mammals come to the river's edge to drink, or eagles come to catch the fish. Ultimately, the flow of energy (beginning with sunlight - trapped by the photosynthesis of plants and algae at the base of the food chain) links up life all over planet Earth (Miller 2008).

- The role a local population of a species plays in an ecosystem is its "ecological niche." All species-with one very important exception-have niches in local ecosystems. The size of local populations depends - as Darwin saw was implicit in Malthus' vision-very much on the "carrying capacity" of the local ecosystem: the density and overall availability of the resources the organisms of a given population need to subsist. And it is in the local populations of species in their local ecosystems where natural selection is relentlessly at work each breeding season.

- Thus all organisms fit in ecologically as well as evolutionarily in the pageant of life.

- Except us-Homo sapiens. Very recently, just ten thousand years or so ago, we humans became the very first species effectively to step outside local ecosystems. This is one of the most amazing things about us humans - and the only exception to the general rule that, to know about life, one need only examine the nature of one's own existence. How this happened is a fascinating story-essential to understanding both who we are and how we currently fit into the world - a story told in Module 7 below.

\section{Module 5. The History of Life on Earth}

- Knowing what we do about modern organisms - how they live, how they reproduce, how they fit into the world-we are armed with the insights we need to explore the lost worlds of the living past. This (from our perspective) is the Greatest Story Ever Told-where we can trace the continuity of life and at the same time see the strange extinct forms of life that no one would ever have dreamed of had they not been unearthed form the fossil record.

- We begin in the oxygen-starved world of the Precambrianwith the simple "bacteria" and the first macroscopic fossils to appear-the massive mats of stromatolites formed, layer by daily layer by blue-green algae.

- We see life change (without losing bacteria-and stromatolites are still living in warm marine waters in today's oceans) just when the levels of oxygen (which was a poison to many of the earliest bacteria) reaches a critical level about 2.2-2.5 billion years ago. These are small (yet larger than bacteria) eukaryotic single-celled "protists"-with the same cellular structure as our own: with DNA on chromosomes segregated now into cellular nuclei bounded by double walls.

- Biologist Lynn Margulis has made the plausible suggestion that the origin of the eukaryotes came as a symbiotic event- the permanent fusion of two different forms of simpler life; the single stranded DNA inside the mitochondria (chloroplasts in plants) - the "power plants" inside each human cell-is utterly unlike the DNA found in the cell's nucleus.

- Then beginning some 570 million years ago, we see the first multicellular organisms appear-strange forms of life paleontologists still argue over - and then, in a massive "explosion" (though it took about ten million years) in the first proliferation of animal life: trilobites, brachiopods, echinoderms, and so forth. The Burgess shale (along with other early deposits) reveals incredible details even of the soft anatomy of these early animals - features usually not preserved in the fossil record.

- We see that, just like the organisms alive today, all these early species had DNA and reproduced-and had adaptations which fit them into their local ecosystems and enabled them to make a living.

- We see the earliest fishes - jawless at first, and then forming a great diverse array of monster armored species, 
sharks, lungfish, and other bony fishes. We meet Tiktaalik, the 400-million-year old "fish with legs" that formed part of the real parade (as opposed to the ubiquitous cartoons) when fish clambered ashore and evolved into amphibians (see the entire issue of $E E O$ on "transitional fossilsProthero (2009)). On land, they met up with the earliest plants, scorpions, and insects - who had pioneered this brave new environment millions of years earlier.

- We follow life through the greatest mass extinction yet to have occurred - at the end of the Paleozoic, some 245 million years ago, when perhaps as many as $96 \%$ of all species on Earth became extinct. Think of it: the vast diversity of life on Earth today all evolved out of only $4 \%$ of the genetic diversity that managed to squeak through the end-Paleozoic extinction!

- We meet the dinosaurs - and the earliest mammals in the Mesozoic - and see as well the ammonites and other dominant members of the marine ecosystems. We see the dinosaurs suffer extinction after extinction-only to survive and come roaring back in new spasms of evolution. Until finally, at the end of the Mesozoic Era, about 65 million years ago, all the remaining terrestrial dinosaurs (evolutionarily speaking, birds are dinosaurs - and they of course survived) finally succumbed to extinction.

- Then the mammals took over-evolving to fill ecological roles that before then had been taken by the dinosaurs.

- The Primates had started back in the Cretaceous - in a world dominated by dinosaurs. They (fortunately for us!) managed to survive the Cretaceous extinction eventand, as the Tertiary wore on, monkeys appeared, then apes, then us (to be continued...).

\section{Module 6. Plate Tectonics and the Evolution of the Earth}

- The Earth has been changing - "evolving"- just as has life. In fact, it is the other way around: nothing much happens - or has in fact happened - in terms of evolutionary change in the history of life without its being triggered by climate change-which in itself depends upon the effects of periodic changes in the Earth's rotation and path around the sun and on the longer-term scale of the changing positions of the continents vis-àvis the oceans-and themselves.

- Four hundred million years ago, there were 400 days to the year-not because it took the Earth longer to rotate around the sun but rather because our rate of spin has been steadily slowing down.

- Even earlier-and correlated with the critical episodes of the rise in oxygen levels in Earth's atmosphere- the Earth-several times-was nearly completely encased in sheets of ice-so-called "Snowball Earth." Again today we live in unusual times as the ice caps (currently rapidly shrinking due to human-caused global warming) are nonetheless unusually large, trapping huge volumes of water. For the vast part of the past half billion years, the surfaces of the continents have been flooded with water-shallow marine seas that have left behind a rich fossil record of marine life.

- The history of continental movements has been worked out in as almost fine detail as the history of life itself. The Earth is divided into eight large (and many smaller) "plates" which move about, rubbing up along one another (the San Andreas fault in California is formed this way), or diving down beneath one another (as the Pacific plate dives below the Andes, causing their continuing uplift), or diverging from one another as new crustal material is generated (as along the midAtlantic ridge - with young Iceland perched on top)the boundaries usually the sites of most of the world's earthquakes and volcanoes. The energy that drives this is not from the sun (ultimate source of energy for living organisms) but rather from the heat generated by radioactive decay deep down in Earth's interior. It is possible to reconstruct where all the pieces of all the continents were, going back billions of years.

- Geography and climate in large measure are what govern the pulse and pace of evolutionary change (including extinction) - thus the changing positions of lands and seas through time underlie many major events in the history of life. Faunas and floras intermingle when continents are united (as when the Isthmus of Panama arose some 2.5 million years ago, allowing the "great American faunal interchange" to occur)-while periods of prolonged isolation lead to the evolution of distinct faunas: the marsupial evolutionary radiation in Australia being a prime example.

- The mass extinctions of the past-the five or six major global ones that took out so many species relatively rapidly during the past half billion years, as well as the hundreds of smaller-scale events that have also played their role in the extinction and evolution of species-have played a major role in transforming life through time. All of these extinction events were themselves triggered by physical events: whether meteorites (or comets) striking the Earth (as is believed to be the case in the end-Cretaceous mass extinction-perhaps coupled with massive volcanic eruptions) - or lesser, more subtle climate changes caused simply by periodic changes in Earth's orbiting and rotational cycles.

- Except one mass extinction event: the Sixth Extinction event - the one that is now gripping life on Earth. This is the first extinction event being triggered - not by physical events - but rather by one living species: Us. 
Module 7. Humans on the Planet: Who Are We? Where Did We Come From? How Do We Fit In?

- But who, in the end, are we? Where did we come from? and how do we in fact fit into this world we find ourselves in right now? For as interesting as evolution and the history of life are in general, these are truly the burning questions facing us all. This is what we really care about the most.

- For the most part, our evolution has followed the same basic "rules" (been governed by the very same processes - and shows the same patterns) as all other forms of life - certainly all other mammals. We even evidently had an ancestor (Australopithecus africanus) succumb to extinction about 2.5 million years ago-just when many other African species were going extinct as the climate grew cooler-and savannah grasslands suddenly replaced the wetter tropical woodlands that had dominated the scene. But as if in responseprobably reflecting the now available new habitats - not one but two fossil hominid species evolved in its place: the "robust australopithecines"-who apparently were obligate herbivores (unlike their omnivore predecessors), and by no means our direct ancestors - along with the first members of our own lineage of Homo (remember we are Homo sapiens-"wise humans"). Thus our ancestors-like all other forms of life from time immemorial-suffered extinction and were replaced by rapidly evolving descendant species.

- The fossil record of human evolution - so scanty in Darwin's day (see Tattersall (2009a, b)) - is now surprisingly rich. Vast amounts of time, money, and pure sweat gone into the hunt for fossil humansespecially, but by no means exclusively, in Africa. And this hunt has paid off in an amazing treasure trove of fantastic fossils - including the famous "Ardi," "Lucy," "Little Foot," and "Turkana Boy"- nearly intact skeletons of vanished ancestors. [As a collapsible component, the entire history of hominids in the fossil record can/will be told at this point].

- We also know about human evolution from molecular evidence - and though in the early days of "molecular paleoanthropology" it was sometimes difficult to square the molecular data with the fossil data, the data on the evolution of our own species, Homo sapiens, seem to agree pretty well. Molecular evidence points to our having evolved in Africa some 200,000 years ago. This is the story of "Mitochondrial Eve." And the oldest fossils discovered so far of our species - in Africa - are nearly 200,000 years old.

- So we came from Africa. The earliest hominids came from Africa-but at intervals, they spread out into Europe and Asia - and perhaps as far as Indonesia. Yet our own species evolved back in the ancestral homeland of Africa - many hundreds of thousands of years later.

- Like our ancestors, we earliest humans were "hunter/ gatherers"- - making a living by mixing hunting with foraging for edible vegetation. Hunter/gatherers (there are few groups of people who are still purely hunter/ gatherers surviving on Earth) are peoples who are directly integrated into their local ecosystems. Their survival depends on what they can glean from their local environment-and at least one tribe (the Ba-Aka) have been recorded as explicitly knowing that they have that relationship with their surroundings - since they have said, as they greet the gods of the forest, that they are there to take only what they need. That is the best description of who we are and how we fit in - until comparatively recently, that can be found.

\section{- The Sixth Extinction - first phase}

- But then things changed. Beginning perhaps 50,000 years ago (see Tattersall, this issue), humans began leaving Africa in large numbers - expanding into Europe, Asia, Australia (ca. 40,000 years ago) and finally, the Americas (ca. 12,500 years ago in large numbers, although people had already arrived earlier).

- Human culture - in this instance, meaning behavioral ways of coping with unaccustomed (such as cold) environments - and, always, ways of making a living meant that everywhere people went, they were able to translate their techniques of hunting and gathering and apply them to the local fauna and flora. Humans walking on the African savannah will see how the herbivores seem to just melt away-as by day humans have historically been the top predators on the African plains. But imagine humans, with sophisticated hunting techniques, invading Europe, Asia, the Americas...as is still the case in the Galapagos Islands - where human presence is only now endangering the fauna. There the native fauna, including the birds, is still unwary of human presence. Now consider the cold plains of North America 10,000 years ago, where the mastodons, giant bison etc. had no prior experience with humans and their efficient hunting techniques.

- Thus the Ice Age faunas - with their species of large mammals - all quickly fell victim to human overhunting - all except in Africa, where the large mammals are only now threatened by overhunting and loss of habitat - also caused by the presence of humans.

- Cultural diversification -in ways like biological (evolutionary) diversification - had started in Africa and was continued as people spread throughout the globe in preagricultural days. Languages diverged, 
and new folkways (some matching new environments, others just by happenstance) developed.

- As people had spread around the globe, some of their physical characteristics diversified.

- Phase 1 of the "Sixth Extinction," where invading bands of humans drove many species of the megafauna extinct, shows how we humans were beginning to have a strong impact on our surrounding environment. More was soon to come.

- Things change: the Sixth Extinction-phase 2

- Enabled by increasingly sophisticated technologies as human culture blossomed; and perhaps spurred on by increasing population numbers, beginning to outstrip the carrying capacity of the local environment, we modern humans took a radical step with ramifications - both wonderful and awful — that are still snowballing: Beginning some 10,000-12,000 years ago-in different places in present-day Iraq, India, and Egypt (and a bit later, in Africa, China, and the Americas), people literally took life into their own hands. They invented agriculture.

- Domestication of animals - and possibly some plantshad begun in isolated spots thousands of years earlier. Then in selecting seeds of particular crop plants and developing the techniques to clear fields and grow only one, two, maybe even three species of desirable, edible plants in place of the riot of tangled and largely inedible plants that were native to those lands, indeed amounted to a "revolution" - the (first) "Agricultural Revolution."

- Think of it: by allowing only the plants that you want to grow, you are changing the very character of life around you. You are creating a category of "undesirable" plants (we call them "weeds"). We allow only the animals (pets and farm animals) that we want aroundand are more eager than ever to keep the foxes and other carnivores away-for now we have hen houses.

- Famine has always stalked the land, and periodic droughts, in good Malthusian fashion, continue to wreak havoc on human agriculturally based populations (including all of us city dwellers who go to the grocery store!) right down to the present day. Yet the best evidence of the effect of agriculture on our human existence in fact is our total population size. Authors looking at the (admittedly scanty) data estimate that there were somewhere between one million and five million human beings on Earth 10,000 years ago. Today? Somewhere between six and seven billion. (Indeed, since the senior author of this article was born in 1943, the human population has way more than doubled). Wars, plagues, droughtsthey can temporarily put a dent in our numbersbut it never lasts long.
- What happened? We stepped-irrevocably-outside of the local ecosystem. Ours is the first species ever to take life into our own hands and be able to do that.

- With agriculture and ballooning numbers, we settled down in ever greater concentrations - inventing cities and city-states with political control. We diversified economically - as some people made bread, some made shoes, while others tended goats and raised emmer wheat.

- Cultural diversification too continued - until relatively recently. The world has lost perhaps 1,000 languages in the past $100+$ years - a very real measure of the beginning of a wave of extinction of diverse human cultures. The last of the hunter/ gatherers are pretty much gone-through cultural assimilation, for the most part-but in some instances through extinction pure and simple.

- Biologically speaking, we have lost thousands of species in the past few centuries - in some estimates, perhaps as many as 30,000 species or more each yearmany in tropical rainforests whose species have not even been studied and tabulated as yet.

- This second phase of the Sixth Extinction continues to accelerate - as our ever-growing population size puts pressure on the environment: through transformation of the natural landscape for agricultural, suburban, and urban development, paving of roads, and so on; through pollution; through the introduction of alien species - and through our continued overharvesting of "natural resources"-including the clear-cutting of forests for timber (or simply for use in agriculture), fisheries and the like.

- All is not lost: if we work to stabilize human population growth, seek sustainable and "green" methods of industrialization and agriculture, and harvesting of existing species; and if we seek better ways to conserve tracts of land and open waters - there is a chance that not only can we arrest the onslaught of this Sixth Extinction-but also live in a world where human cultural and biological diversity can continue to thrive.

\section{Module 8. Our Future}

- There is no going back - for we humans have changed the ecological rules - at least for ourselves. We do NOT fit in the same way that absolutely all other species (and our own ancestors-including members of our own species) "traditionally" have fit into ecosystems. Our job now is to make this the best, cleanest safest world- to take charge of, to care for, our native home - planet Earth.

- We should never forget that this "brave new world" we invented only 10,000 years ago has many wonderful 
things about it. We humans can think, and our diversified cultures - aided and abetted by our agricultural revolution - have produced a vast flowering of the arts and sciences - an achievement that continues to grow, and which we should all continue to enjoy and encourage - and join in with each of our own special ways to help it grow.

- We evolved on this Earth - and it is unthinkable that we would continue to prosper without the native habitatswith all the plants, animals, fungi, and microbes sustaining the world. We need the clear skies, clean waters, gorgeous sunsets, all species great and small-all the treasures we have grown up with. They are part of our heritage and part of what gives value to human life.

- Thinking biologically again - what of our own evolutionary future? Would it be possible to engineer our future evolution - through genetic engineering, say? Well, evolution involves changing the genetic information of an entire species-if, that is, the change is destined to last. That seems hardly possible by artificially manipulating the genetics of nearly seven billion people (though recent reports of a goal of five billion shots for the H1N1 swine flu virus, in a sense, addresses the issue of sheer totality of numbers; see Hood and Jenkins (2008) for a review of "evolutionary medicine").

- More realistically, we should look at the recent advances in genetic engineering and biotechnology as extensions of what we were able to do with selective breeding, which Darwin called "artificial selection," and saw as an effective analogue of his theory of evolution through natural selection. More advances in both agriculture and medicine - both "applied biology" - are inevitable.

- We should always remember who is the boss: We are. You are. Together we can make the right, intelligent decisions-not looking simply for change for the sake of change, not looking for illusory miracles to cure the world's ills - but rather for strategies and approaches to making Earth a better world for all humans - and for all the rest of life on Earth.

\section{Student Workbooks}

The aim of the workbooks is to get students directly involved on their own personal and local levels confronting the broader issues as developed in the eight modules of the main curriculum. The approach is to present an array of questions and problems designed to have students explore the issues of the own existence (Who am I? Where do I come from? How do I fit in?)—with personal, localized explorations of issues related to the more global themes and cosmic answers to the "Who am I" rhetorical issues developed in the classroom. Students will work singly or in small groups and utilize as many online, library, and other resources to answer the questions and solve the problems.

The workbooks could accompany text materials, presented online, or simply provided by the teacher.

What follows is simply a list of examples-not expressly tied directly to specific modules as developed above. The list can be expanded ad infinitum-and, of course, potentially focused more specifically on particular modules:

- So, who are you, anyway? Manny Esposito from the Bronx, New York? Becky Rogers from Anchorage, Alaska? A'Manisha Burris from Mobile Alabama? Sam Littlebear from Rosebud, South Dakota? Satoshi Yakomura from San Francisco? Whoever you are, boy or girl, Latino, Native American, Asian, Black, Caucasian, whatever!- you have a story. Your story is the beginning of your own exploration of the larger world around youhelping you to find out what it is to be a living, breathing organism walking the earth. A human being - member of the species Homo sapiens - the official scientific Latin name of our species, meaning "wise human." A good name, as it reminds us that we can indeed learn about ourselves and the world around us.

- Find yourself in the universe. Where do you live? Country? State? County? City/Town/Village? GPS coordinates? Where you live fits in with ever larger and larger political and geographic sections of your state, your country - and of course ultimately planet Earth, and planet Earth is a part of the solar system, etc.

- What is the population of your community? What is its form of government?

- Who were the first people to inhabit your region? Where did they come from?

- What about the people living there now? Where did they come from? Where did your people-your grandparents - come from? Did they move from another place? Where was that? Did your ancestors come from some other continent? Which one(s)?

- What about all the other people in your neighborhoodwho are they, and where did they come from-in the recent past and deeper back in human history?

- What languages are spoken in your neighborhood? Are there any cultural traditions different from your own you can find in your neighborhood?

- What is it that makes you a living being? What makes you an animal? What features do you share with monkeys? Squirrels? Dogs? Snakes? Frogs? Sharks? Snails? Jellyfish? Plants? Mushrooms? Amoebae? Bacteria?

- What kind of environment do you live in? Are you located in a desert? On the ocean shore? In farmland? If you are in a large city, what sort of environment was 
there before your city was built up? When was it built up? Are there parklands in and around your city? Do they preserve some of the original ecosystems/wildlife that were there originally? List 25 species of (1) animals, (2) plants, (3) fungi and microbes that commonly occur where you live.

- Describe the environmental and geological history of your region over the past billion years and over the past 10,000 years. What was it like during the Ice Ages? Were dinosaurs ever living in your neighborhood? How do you know? When did they live there? Are there outcrops of rocks or other forms of geological evidence you can explore near you-that provide some of the evidence of the history of your part of the world?

- Where can you find the nearest fossil remains of ancient life? (Remember, fossils also occur in building stones).

- Do you live near a science or natural history museum? If so, what do the exhibits about (1) local wildlife/ ecosystems and (2) fossils and (3) geology tell you about the history and current conditions where you live? If there is not a museum nearby, visit some museums online and answer the same questions!

- How does where you live connect with other places around you - are the environments all the same? What kinds of animals and plants occur nearby that do not occur right where you live?

\section{Summary and Conclusions}

Combining our experiences and expertise-one of us (NE) a research and theoretical paleontologist/evolutionary biologist, the other (GE) a public school special education science teacher - and with three years of editorial supervision of the journal Evolution: Education and Outreach (already achieving success in its objective to build stronger connections between the worlds of evolutionary science and $\mathrm{K}-16$ education), we have developed our ideas on a "universal evolutionary curriculum." It is universal primarily because it can be adapted to all grade levels - from "K" through "16." It is also flexible - with modules than can be modified, reordered, contracted, or expanded to serve the needs - and special interests - of school district curricula and individual teachers.
Centered around the questions: Who Am I? Where do I come From? and How do I fit in? the curriculum centers on the human experience, based on the realization that the best way to know what it is like to be alive is to know thyself. Evolution - especially human evolution-is taught unabashedly and unreservedly through our curriculum. Using online or printed workbooks, students can explore the central questions locally while learning the larger lessons of the evolution of life on earth.

Acknowledgments We thank fellow members of the Eldredge Group - an educational consortium - for their input into the development of the ideas expressed in this article and for their critical comments on earlier drafts: Douglas Eldredge, Michelle Eldredge, Teresita Eldredge, and Jennifer Schneider.

\section{References}

Eldredge D. How can English tell the story? Evo Edu Outreach. 2009;2(4). doi 10.1007/s12052-009-0186-4.

Eldredge G. The five major divisions ("kingdoms") of life. Evo Edu Outreach. 2008;1(1):33-5.

Eldredge G. Why I teach evolution. Evo Edu Outreach. 2009;2 (3):342-6.

Eldredge N. Hierarchies and the sloshing bucket: toward the unification of evolutionary biology. Evo Edu Outreach. 2008;1(1):10-5.

Eldredge N. To teach science, tell stories. Issues in Science and Technology. 2009a;81-84.

Eldredge N. Experimenting with transmutation: Darwin, the Beagle, and evolution. Evo Edu Outreach. 2009b;2(1):35-54.

Fail J Jr. A no-holds-barred evolution curriculum for elementary and junior high school students. Evo Edu Outreach. 2008;1(1):56-64.

Gregory TR. Understanding evolutionary trees. Evo Edu Outreach. 2008a;1(2):121-37.

Gregory TR (ed). Special issue: the evolution of eyes. Evo Edu Outreach. 2008b;1(4):351-559.

Hood E, Jenkins K. Evolutionary medicine: a powerful tool for improving human health. Evo Edu Outreach. 2008;1(1):114-20.

Jenkins K (ed). Special Issue: Teaching Evolution. Evo Edu Outreach 2009;2(3):341-577.

Miller W III. The hierarchical structure of ecosystems: connections to evolution. Evo Edu Outreach. 2008;1(1):16-24.

Prothero DR (ed). Special Issue: Transitional Fossils. Evo Edu Outreach 2009;2(2):149-339.

Tattersall I. Charles Darwin and human evolution. Evo Edu Outreach. 2009a;1(1):28-34.

Tattersall I. Becoming modern Homo sapiens. Evo Edu Outreach. 2009b;2(4):TK.

Thanukos A. Parsimonious explanations for punctuated patterns. Evo Edu Outreach. 2008;1(2):138-46.

Venditti C, Pagel M. Speciation and bursts of evolution. Evo Edu Outreach. 2008;1(3):274-80. 